\title{
Characteristics of young lung cancer: Analysis of Taiwan's nationwide lung cancer registry focusing on epidermal growth factor receptor mutation and smoking status
}

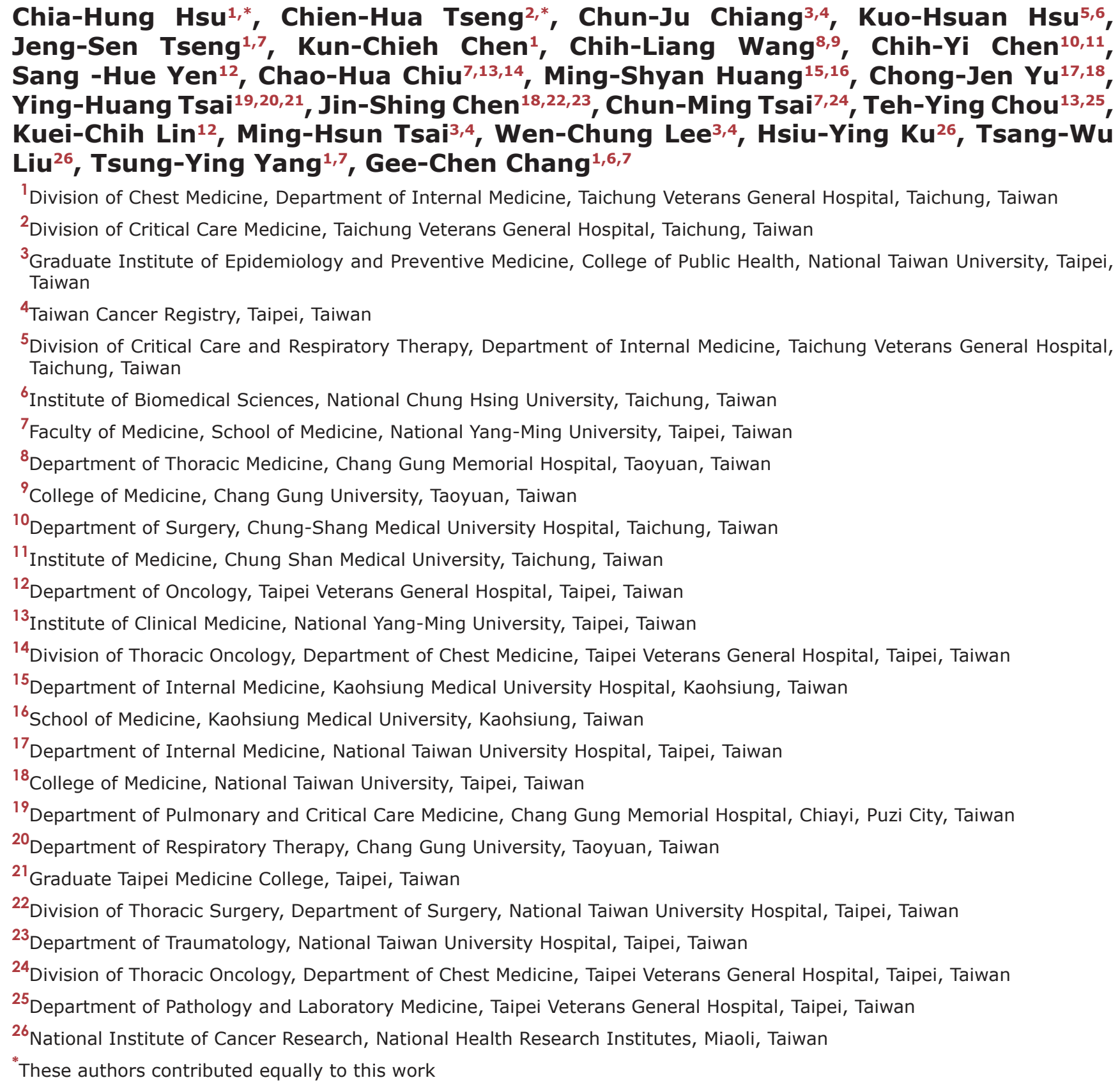




\section{ABSTRACT}

Lung cancer is relatively rare in young patients as the median age at diagnosis is 65-70 years. The main objective of this nationwide study was to investigate the characteristics of young lung cancer in Taiwan, especially the relationships among smoking behavior, epidermal growth factor receptor (EGFR) mutation, and age. The National Taiwan Lung Cancer Registry, a database contain detailed cancer statistics, was analyzed in this study for the period 2011-2012. Young lung cancer was defined as age $\leqq 45$ years. There were 21,536 lung cancer patients $(13,187$ men and 8349 women). Among these patients, 1074 (5.0\%) were in the younger group, and 20,462 patients $(95.0 \%)$ were in the older group. Female gender $(48.8 \%$ versus $38.2 \%$, $P<0.001)$, never-smokers $(47.3 \%$ versus $43.8 \%, P=0.015)$, and adenocarcinoma (70.4\% versus $58.1 \%, P<0.001$ ) were more frequent in the younger group. While the EGFR mutation rate was lower in the younger group ( $52.5 \%$ versus $60.6 \%, P=0.001)$, the primary site of lung cancer and stage distribution were not significantly different. If only adenocarcinoma patients were included in the analysis, female gender, older age, and never-smokers were more likely to have EGFR mutation. In conclusion, lung cancer in young patients ( $\leqq \mathbf{4 5}$ year-old) was associated with unique characteristics, with greater percentages of female patients, adenocarcinoma, and never-smokers and a lower EGFR mutation rate compared with older patients.

\section{INTRODUCTION}

Lung cancer is the leading cause of malignancyrelated mortality worldwide [1]. There are fewer studies on young lung cancer patients, i.e., those less than 40 years of age, owing to the fact that the median age of lung cancer at diagnosis is 65-70 years [2]. Among all non-small cell lung cancer (NSCLC) patients, $0.6 \%$ $\sim 5.3 \%$ is the young lung cancer, defined as less than 40 45 years [2-5]. Female gender and adenocarcinoma predominance are consistent features, but survival data and late stage at diagnosis yield conflicting findings in young lung cancer in previous reports [2-6]. Furthermore, smoking status and EGFR mutation were important factors in the current lung cancer study. Majority of lung cancer patients were advanced or metastatic at diagnosis. In the treatment of advanced NSCLC, the first-line use of gefitinib or erlotinib, an orally administered tyrosine kinase inhibitors (TKIs) of $E G F R$, was recommended for patients harboring $E G F R$ mutation with improvement of the progression-free survival and acceptable toxicity $[7,8]$. The epidemiological study of EGFR mutations demonstrated higher frequency among adenocarcinoma histology, never-smoking status, and Asian ethnicity [9-11]. Anaplastic lymphoma kinase (ALK) rearrangement was another targetable genotype in NSCLC. Crizotinib, an oral small-molecule tyrosine kinase inhibitor of $A L K$, improved the progression-free survival and quality of life in $A L K$-positive patients $[12,13]$.

To our knowledge, no large-scale survey of Asian young lung cancer with detailed data on smoking and $E G F R$ status has been conducted. Only one retrospective study at a single institution has been previously conducted [14], according to our review of the literature. The main objective of this nationwide study was to investigate the characteristics of young adult lung cancer in Taiwan, especially the relationships among smoking behavior, $E G F R$ mutation, and age. Therefore, we analyzed the National Taiwan Cancer Registry database for the period 2011-2012. Detailed smoking status and EGFR results have been routinely surveyed and documented in the database since 2011 .

\section{RESULTS}

The database included 21,536 patients $(13,187$ men and 8349 women) diagnosed with lung cancer from 2011 to 2012 in Taiwan. Among these patients, 1074 $(5.0 \%)$ were in the younger age group (age $\leqq 45$ years), and 20,462 patients $(95.0 \%)$ were in the older age group (Table 1). There was a greater proportion of females in the younger age group than in the older age group $(48.8 \%$ versus $38.2 \%, P<0.001)$. The proportion of never-smokers was significantly higher in the younger than in the older group $(47.3 \%$ versus $43.8 \%, P=0.015)$. Adenocarcinomas were more frequent in the younger than in the older group ( $70.4 \%$ versus $58.1 \%, P<0.001)$. The primary site of lung cancer was not significantly different between the two groups $(56.2 \%$ versus $57.7 \%$ in upper lobes, $P=0.910)$. The distribution of stage at diagnosis was not significantly different (stage I, $14.9 \%$ versus $14.4 \%$; stage II, $4.0 \%$ versus $4.2 \%$; stage III $12.9 \%$ versus $16.3 \%$; stage IV, $56.6 \%$ versus $57.1 \%, P=0.095)$. Among patients with known smoking status and adenocarcinoma, the EGFR mutation test was performed in $59.9 \%$ of the younger patients and in $56.1 \%$ of the older patients. The EGFR mutation rate was significantly lower in the younger patients compared with the older patients $(52.5 \%$ versus $60.6 \%, P=0.001)$. 
Table 1: Patient characteristics between the younger and older groups in all lung cancer in Taiwan, 2011-2012 $(n=21,536)$

\begin{tabular}{|c|c|c|c|}
\hline Demographic characteristics & $\leqq 45$ years old & $>45$ years old & $P$ value \\
\hline Number of cases & 1074 & 20462 & $<0.001$ \\
\hline \multicolumn{4}{|l|}{ Gender, $n(\%)$} \\
\hline Male & $550(51.2)$ & $12637(61.8)$ & $<0.001$ \\
\hline Female & $524(48.8)$ & $7825(38.2)$ & \\
\hline \multicolumn{4}{|l|}{ Smoking history, $n$ (\%) } \\
\hline Never-smoking & $508(47.3)$ & $8954(43.8)$ & 0.015 \\
\hline Ever-smoking & $419(39.0)$ & $8702(42.5)$ & \\
\hline NA & $147(13.7)$ & $2806(13.7)$ & \\
\hline \multicolumn{4}{|l|}{ Histology, $n(\%)$} \\
\hline Adenocarcinoma & $756(70.4)$ & $11892(58.1)$ & $<0.001$ \\
\hline Squamous cell carcinoma & $75(7.0)$ & $3349(16.4)$ & \\
\hline Small cell carcinoma & $43(4.0)$ & $1647(8.0)$ & \\
\hline Other types & $200(18.6)$ & $3574(17.5)$ & \\
\hline \multicolumn{4}{|l|}{ Location, $n(\%)$} \\
\hline Upper lobes & $604(56.2)$ & $11800(57.7)$ & 0.910 \\
\hline Lower lobes & $341(31.8)$ & $6714(32.8)$ & \\
\hline NA & $129(12.0)$ & $1948(9.5)$ & \\
\hline \multicolumn{4}{|l|}{ Stage, $n(\%)$} \\
\hline Stage I & $160(14.9)$ & $2943(14.4)$ & 0.095 \\
\hline Stage II & $43(4.0)$ & $860(4.2)$ & \\
\hline Stage III & $139(12.9)$ & $3338(16.3)$ & \\
\hline Stage IV & $608(56.6)$ & $11674(57.1)$ & \\
\hline NA & $124(11.5)$ & $1647(8.0)$ & \\
\hline \multicolumn{4}{|l|}{ EGFR testing*, $n(\%)$} \\
\hline Performed & 406 (59.9) & $6077(56.1)$ & 0.129 \\
\hline Not performed & $282(40.1)$ & 4764 (43.9) & \\
\hline \multicolumn{4}{|l|}{ EGFR mutation*, $n(\%)$} \\
\hline Positive & $213(52.5)$ & $3684(60.6)$ & 0.001 \\
\hline Negative & $193(47.5)$ & $2393(39.4)$ & \\
\hline
\end{tabular}

Abbreviations: NA, not available; $E G F R$, epidermal growth factor receptor.

*Only adenocarcinoma patients with known smoking status were included for analysis.

As shown in Table 1, younger patients are more likely to be female, never-smokers, adenocarcinoma, and harbor wild type EGFR gene. In our study cohort, $47.3 \%$ of the younger patients and $43.8 \%$ of the older patients are never-smokers, and smoking behavior might be a complex confounding factor. We selected never-smoking lung cancer for further analysis. As shown in Table 2, the younger age group was significantly more likely to have wild-type $E G F R(\mathrm{OR}=1.68,95 \% \mathrm{CI}: 1.30 \sim 2.17$, $P<0.001$ ), and stage IIIB/IV cancer at diagnosis than the older group (OR $=1.84,95 \% \mathrm{CI}: 1.22 \sim 2.76, P=0.003)$.

As shown in Table 3, we used multiple logistic regression to analyze EGFR mutation status in lung adenocarcinoma patients. Older patients (OR: 1.38, 95\% 
Table 2: Characteristics between younger and older groups for never-smoking lung cancer patients with performed $E G F R$ testing $(n=4,440)$

\begin{tabular}{|l|c|c|c|c|}
\hline \multicolumn{2}{|c|}{$\leqq \mathbf{4 5}$ years old } & $>$ 45 years old & Odds ratio* & P value \\
\hline Gender, $\boldsymbol{n}(\%)$ & & & & \\
\hline Male & $63(24.0)$ & $1011(24.2)$ & 1.00 (reference) & \\
\hline Female & $199(76.0)$ & $3167(75.8)$ & $1.03(0.77 \sim 1.39)$ & 0.955 \\
\hline Histology, $\boldsymbol{n}(\%)$ & & & & \\
\hline Adenocarcinoma & $249(95.0)$ & $3952(94.6)$ & $1.00($ reference $)$ & \\
\hline Others & $13(5.0)$ & $226(5.4)$ & $0.91(0.51 \sim 1.62)$ & 0.756 \\
\hline Stage, $\boldsymbol{n}(\%)$ & & & & \\
\hline I-IIIA & $27(10.3)$ & $729(17.4)$ & 1.00 (reference) & \\
\hline IIIB-IV & $235(89.7)$ & $3449(82.6)$ & $1.84(1.22 \sim 2.76)$ & 0.003 \\
\hline $\boldsymbol{E G F R}$ mutation, $\boldsymbol{n}(\%)$ & & & & \\
\hline Positive & $148(56.5)$ & $2859(68.4)$ & $1.00($ reference $)$ & \\
\hline Negative & $114(43.5)$ & $1319(31.6)$ & $1.68(1.30 \sim 2.17)$ & $<0.001$ \\
\hline
\end{tabular}

*Odds ratios for younger age group.

Table 3: Multiple logistic regression for EGFR mutation in lung adenocarcinoma patients $(n=6483)$

\begin{tabular}{|c|c|c|c|c|}
\hline & EGFR Mutation & EGFR Wild-type & Odds ratio* & $P$ value \\
\hline \multicolumn{5}{|l|}{ Gender, $n(\%)$} \\
\hline Male & $1586(40.7)$ & $1511(58.4)$ & 1.00 (reference) & \\
\hline Female & $2311(59.3)$ & $1075(41.6)$ & $1.19(1.04-1.36)$ & $<.001$ \\
\hline \multicolumn{5}{|l|}{ Age, $n(\%)$} \\
\hline$\leqq 45$ years old & $213(5.5)$ & $193(7.5)$ & 1.00 (reference) & \\
\hline$>45$ years old & $3684(94.5)$ & $2393(92.5)$ & $1.38(1.12-1.69)$ & 0.001 \\
\hline \multicolumn{5}{|l|}{ Stage, $n(\%)$} \\
\hline I-IIIA & $635(16.3)$ & $378(14.6)$ & 1.00 (reference) & \\
\hline IIIB-IV & $3262(83.7)$ & $2208(85.4)$ & $0.95(0.82-1.09)$ & 0.068 \\
\hline \multicolumn{5}{|c|}{ Smoking history, $n(\%)$} \\
\hline Never smoker & $2878(73.9)$ & $1323(51.2)$ & 1.00 (reference) & \\
\hline Ever smoker & $1019(26.1)$ & $1263(48.4)$ & $0.42(0.36-0.48)$ & $<.001$ \\
\hline
\end{tabular}

Abbreviations: EGFR, epidermal growth factor receptor.

*Odds ratios for EGFR mutation.

CI: $1.12 \sim 1.69, P=0.001)$ and females (OR: $1.19,95 \%$ CI: $1.04 \sim 1.36, P<0.001)$ were significantly more likely to have $E G F R$ mutation. Ever-smokers were significantly more likely to have EGFR wild-type (OR: 0.42, 95\% CI: $0.36 \sim 0.48, P<0.001)$. In above multiple logistic regression, age is an independent factor to predict $E G F R$ mutation status.
Figure 1 shows the EGFR mutation status in never-smoking adenocarcinoma patients with respect to different age groups and genders. The EGFR mutation rate was significantly lower in the younger age group than in the older age group (53.3\% versus $66.7 \%, P=0.035$ ) in never-smoking male patients with adenocarcinoma; and also in never-smoking female 
patients with adenocarcinoma $(58.6 \%$ versus $69.9 \%$, $P=0.001)$.

\section{DISCUSSION}

Lung cancer is more common among older patients. Young lung cancer, which was defined as lung cancer occurring in individuals less than or equal to 45 years of age, accounted for about $5.0 \%$ of total lung cancer patients in this study. We analyzed the younger patients based on the National Taiwan Cancer Registry database from 2011 to 2012. The clinical characteristics of younger age patients showed unique factors compared to older patients, such as greater proportions of female patients, adenocarcinoma, and never-smoking, and a lower EGFR mutation rate. There were no significant differences in the stage distribution and primary lung cancer location between younger and older patients.

Smoking has a major impact on the risk of developing lung cancer. In our analysis, there was a significant difference in smoking behavior between the two age groups. There were more never-smokers in the younger age group. However, the never-smoking rate even in the older age group was much higher when compared with the rate reported in the French nationwide NSCLC study $(43.8 \%$ vs. $19.0 \%)$ [15]. This is one of the major differences in lung cancer between Asian and Caucasian patients. Furthermore, in our analysis, among lung adenocarcinoma patients with detailed smoking and EGFR mutation status, there was an even higher rate of neversmokers $(64.8 \%)$.

The incidence of young lung cancer in the SEER database showed a decreasing trend during the period 1978 to 2010, but an increasing trend was found in other reports. The phenomenon may be due to the divergent smoking prevalence rates reported in different studies [4, 5, 16, 17]. Moreover, other hypotheses such as genes involved in xenobiotic metabolizing enzymes [18], DNA repair [19], and occupational risk factors have also been reported [20]. Tobacco smoking may result in various types of DNA damage in lung parenchyma and may lead to chronic inflammation, ultimately leading to carcinogenesis. According to the hypothesis of genetic variation in DNA repair and cell cycle control genes, young lung cancer patients may be more susceptible to carcinogens in tobacco smoke than older patients. Landi et al. surveyed 299 lung cancer cases diagnosed before the age of 50 years and 317 age-matched controls patients from six countries in Central and Eastern Europe. They found a significant association with polymorphisms in genes involved in DNA damage sensing and in four genes encoding proteins involved in mismatch repair (LIG1, LIG3, MLH1, and MSH6). Young patients with specific polymorphisms of the above genes may be more susceptible to carcinogens [19].

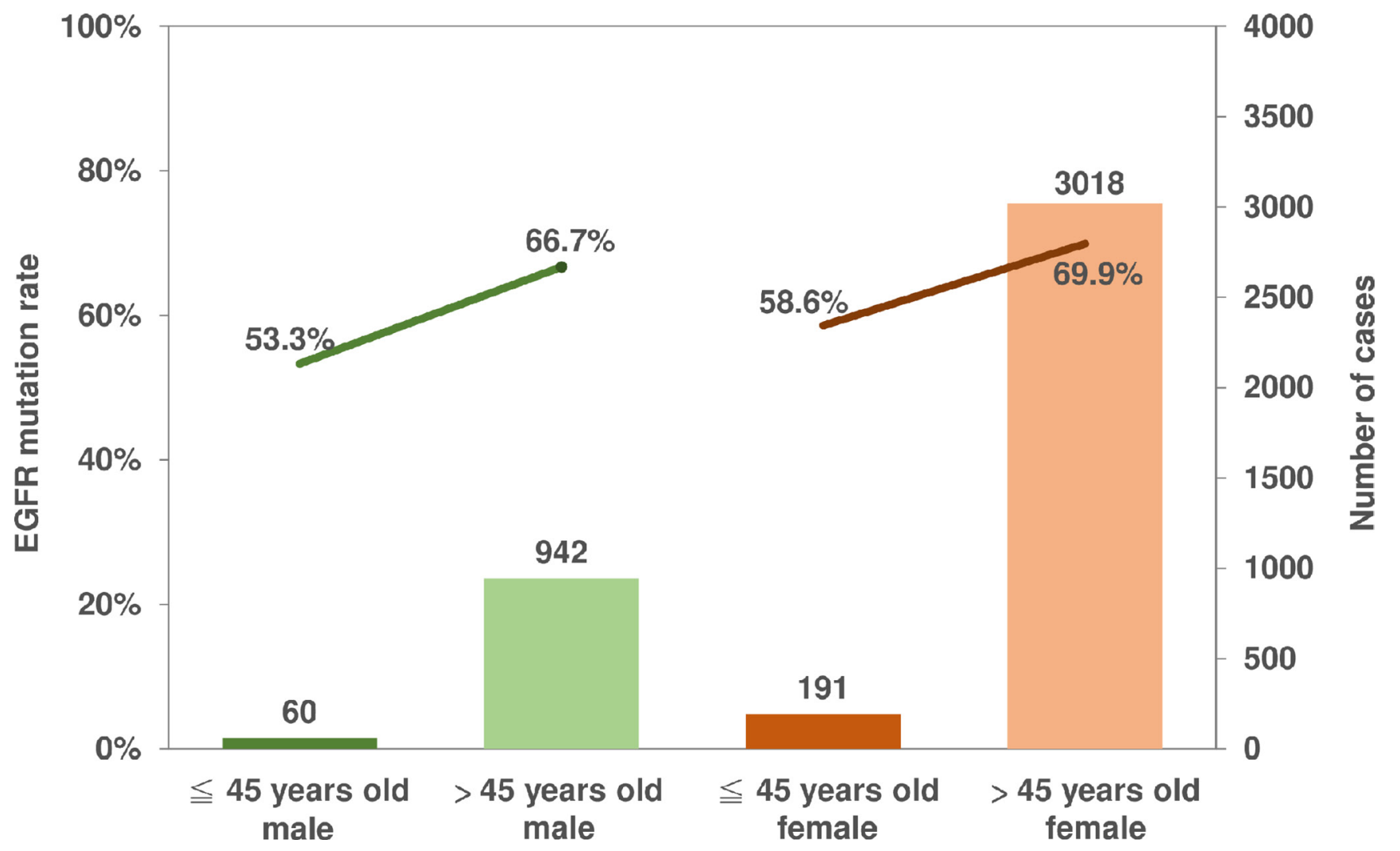

Figure 1: EGFR mutation status in never-smoking adenocarcinoma patients with respect to different age groups and genders. 
Our results are consistent with previous studies that found a greater proportion of female patients and adenocarcinoma in the younger age group, but there were no significant differences in primary lung cancer location and stage at diagnosis between younger and older patients $[2,5]$. Moreover, the EGFR mutation rate of younger lung cancer patients was significantly lower than that in the older group. To our knowledge, this is the first study to analyze the aforementioned factors using a nationwide database.

EGFR mutation was associated with female, adenocarcinoma histology, never-smoking status, and Asian ethnicity [9-11]. Regarding EGFR status in our study, there was a lower $E G F R$ mutation rate in the younger group. We used $E G F R$ mutation as the outcome in a further analysis. Older patient, never-smokers, and females were significantly more likely to have the EGFR mutation according to the results of the multiple logistic regression analysis. As there was a significantly higher proportion of never-smokers in the younger patient, why did younger lung adenocarcinoma patients have a lower $E G F R$ mutation rate than that of older patients? There are a couple of possible reasons. First, besides EGFR mutation, there are several molecular alterations involved in lung adenocarcinoma carcinogenesis, including $v$-raf murine sarcoma viral oncogene homolog $B(B R A F)$, Kirsten rat sarcoma viral oncogene homolog (KRAS), human epidermal growth factor receptor 2 (HER2), and echinoderm microtubule-associated protein-like 4-anaplastic lymphoma kinase (EML4-ALK). Recent data have suggested that $A L K$ rearrangement lung cancers are associated with a younger age at diagnosis [21-23]. In our previous study of the mutation status of five genes in lung adenocarcinoma, EGFR mutations were more common in female patients and non-smokers. In $E G F R$ wild-type adenocarcinoma, the proportion of EML4-ALK translocation was $9.8 \%$ and predominant in patients younger than 65 years (14\% versus 3.4\%) [24]. With further analysis, we found the mean age of $A L K$ positive patients were about 11 years younger than that of EGFR mutation patients (Supplementary Table 1). In a study by Guo et al., 95 Chinese never-smoking males were diagnosed with NSCLC. The proportion of EML4$A L K$ translocation was $8.4 \%$ (8 out of 95 patients), and was more frequently found in never-smokers and younger patients (5 patients between 40 49 year-old) [25]. In the recent study of Sacher et al., they reported that the younger age patients are associated with an increased likelihood of harboring a targetable genotype, which EGFR mutation $(P=0.02)$ and $A L K$ rearrangement $(P<0.01)$ were significantly associated with younger age. In their cohort, those younger patients (less than 40 years old) are more likely to be never smokers (67\%), and older patients (more than 60 years old) are less likely to be never smokers $(22 \%)$. Under multivariable analysis, the association between EGFR mutations and age was not significant [26]. ALK rearrangements may explain at least in part why younger patients had a lower positive $E G F R$ mutation rate in this study.

Second, in our study, female lung adenocarcinoma patients had a higher EGFR mutation rate than that of male patients. We had a greater proportion of female lung cancer patients in the younger group, but the EGFR mutation rate was lower than that of the older group. Moreover, with respect to $E M L 4-A L K$ translocation, there may be a different pattern of carcinogenesis between the younger and older groups. The contributing factors may involve genetic susceptibility, environmental factors, and their complex interactions in the pathogenesis of lung cancer in younger patients.

In our study, smoking and EGFR mutation status were registered nationwide. This is the first large-scale study on lung cancer to include detailed information pertaining to both smoking and EGFR mutation. In future studies of young lung cancer and its association with the $E G F R$ mutation, additional factors should be included in the analysis, such as family lung cancer history, smoking index, age of starting smoking, passive smoking, 'environmental exposures, and status of other driver oncogene, including $A L K$ rearrangement, $B R A F, K R A S$, ROS- 1 and HER-2.

In conclusion, our findings demonstrated that lung cancer in younger patients ( $\leqq 45$ years) has unique characteristics, with a greater proportion of female patients, adenocarcinoma, and never-smokers, and a lower $E G F R$ mutation rate compared with older patients. The stage distribution and location of the primary tumor were not significantly different between the two groups.

\section{MATERIALS AND METHODS}

Since 2011, collection of detailed smoking history status was officially included in the National Taiwan Lung Cancer Registry database and EGFR mutation exams were routinely surveyed from lung adenocarcinoma patients most in advanced stages for EGFR-TKI treatment evaluation. We analyzed data for the period from 2011 to 2012 in the present study. Lung cancer histology was classified according to the World Health Organization criteria [27]. Demographic characteristics, and clinical data, including age, gender, tumor stage, primary tumor location, smoking status, and EGFR mutation were included in the analysis. Never-smokers were defined as patients who had never smoked cigarettes, whereas ever-smokers were defined as those who were current or former smokers. This study was approved by the Institutional Review Board of Taiwan's National Health Research Institutes Research Ethics Committee (IRB No. EC1031002-E)

There are a few different methods for EGFR mutation testing in Taiwan, including direct sequencing, and mutant type-specific sensitive methods, such as protein nucleic acid-locked nucleic acid polymerase chain 
reaction (PNA-LNA PCR) clamp, scorpions amplification refractory mutation system (ARMS) and Cobas EGFR Mutation Test. Among all hospitals in Taiwan, there are different laboratory facilities and preferences with respect to EGFR mutation testing. The lung cancer stages were all based on the American Joint Committee on Cancer (AJCC) 7th edition. We classified young lung cancer as age below or equal to 45 years. Missing data in the database were also analyzed to determine whether or not they were missing-at-random. Chi-square test was conducted to analyze patients' characteristics. Multivariable analysis of the correlation of EGFR mutation and age with other factors was performed using logistic regression. All analyses were performed using SAS version 9.3 statistical software (SAS Institute, Cary, NC, USA).

\section{ACKNOWLEDGMENTS AND FUNDING}

This work was supported by the Health Promotion Administration, Ministry of Health and Welfare, Taiwan (R.O.C.). Funding was provided by the tobacco control and health care funds.

\section{CONFLICTS OF INTEREST}

The authors declare that there are no conflicts of interest.

\section{REFERENCES}

1. Siegel R, Naishadham D, Jemal A. Cancer statistics, 2012. CA Cancer J Clin. 2012; 62:10-29.

2. Subramanian J, Morgensztern D, Goodgame B, Baggstrom MQ, Gao F, Piccirillo J, Govindan R. Distinctive characteristics of non-small cell lung cancer (NSCLC) in the young: a surveillance, epidemiology, and end results (SEER) analysis. J Thorac Oncol. 2010; 5:23-28.

3. Kuo CW, Chen YM, Chao JY, Tsai CM, Perng RP. Nonsmall cell lung cancer in very young and very old patients. Chest. 2000; 117:354-357.

4. Zhang J, Chen SF, Zhen Y, Xiang J, Wu C, Bao P, Luketich J, Hu H, Zhou X, Zhang J, Yao S, Chen HQ. Multicenter analysis of lung cancer patients younger than 45 years in Shanghai. Cancer. 2010; 116:3656-3662.

5. Thomas A, Chen Y, Yu T, Jakopovic M, Giaccone G. Trends and Characteristics of Young Non-Small Cell Lung Cancer Patients in the United States. Front Oncol. 2015; 5:113.

6. Bryant AS, Cerfolio RJ. Differences in outcomes between younger and older patients with non-small cell lung cancer. The Annals of thoracic surgery. 2008; 85:1735-1739; discussion 1739.

7. Mok TS, Wu YL, Thongprasert S, Yang $\mathrm{CH}$, Chu DT, Saijo N, Sunpaweravong P, Han B, Margono B, Ichinose Y, Nishiwaki Y, Ohe Y, Yang JJ, et al. Gefitinib or carboplatin- paclitaxel in pulmonary adenocarcinoma. N Engl J Med. 2009; 361:947-957.

8. Azzoli CG, Baker S Jr, Temin S, Pao W, Aliff T, Brahmer J, Johnson DH, Laskin JL, Masters G, Milton D, Nordquist L, Pfister DG, Piantadosi S, et al. American Society of Clinical Oncology Clinical Practice Guideline update on chemotherapy for stage IV non-small-cell lung cancer. J Clin Oncol. 2009; 27:6251-6266.

9. Shi Y, Au JS, Thongprasert S, Srinivasan S, Tsai CM, Khoa MT, Heeroma K, Itoh Y, Cornelio G, Yang PC. A prospective, molecular epidemiology study of EGFR mutations in Asian patients with advanced non-small-cell lung cancer of adenocarcinoma histology (PIONEER). J Thorac Oncol. 2014; 9:154-162.

10. Shigematsu H, Lin L, Takahashi T, Nomura M, Suzuki M, Wistuba, II, Fong KM, Lee H, Toyooka S, Shimizu N, Fujisawa T, Feng Z, Roth JA, et al. Clinical and biological features associated with epidermal growth factor receptor gene mutations in lung cancers. J Natl Cancer Inst. 2005; 97:339-346.

11. Bareschino MA, Schettino C, Rossi A, Maione P, Sacco PC, Zeppa R, Gridelli C. Treatment of advanced non small cell lung cancer. J Thorac Dis. 2011; 3:122-133.

12. Solomon BJ, Mok T, Kim DW, Wu YL, Nakagawa K, Mekhail T, Felip E, Cappuzzo F, Paolini J, Usari T, Iyer S, Reisman A, Wilner KD, et al. First-line crizotinib versus chemotherapy in ALK-positive lung cancer. N Engl J Med. 2014; 371:2167-2177.

13. Shaw AT, Kim DW, Nakagawa K, Seto T, Crino L, Ahn MJ, De Pas T, Besse B, Solomon BJ, Blackhall F, Wu YL, Thomas M, O’Byrne KJ, et al. Crizotinib versus chemotherapy in advanced ALK-positive lung cancer. N Engl J Med. 2013; 368:2385-2394.

14. Hsu CL, Chen KY, Shih JY, Ho CC, Yang CH, Yu CJ, Yang PC. Advanced non-small cell lung cancer in patients aged 45 years or younger: outcomes and prognostic factors. BMC Cancer. 2012; 12:241.

15. Barlesi F, Mazieres J, Merlio JP, Debieuvre D, Mosser J, Lena H, Ouafik L, Besse B, Rouquette I, Westeel V, Escande F, Monnet I, Lemoine A, et al. Routine molecular profiling of patients with advanced non-small-cell lung cancer: results of a 1-year nationwide programme of the French Cooperative Thoracic Intergroup (IFCT). Lancet. 2016.

16. Strand TE, Malayeri C, Eskonsipo PK, Grimsrud TK, Norstein J, Grotmol T. Adolescent smoking and trends in lung cancer incidence among young adults in Norway 1954-1998. Cancer Causes Control. 2004; 15:27-33.

17. Thun MJ, Jemal A. How much of the decrease in cancer death rates in the United States is attributable to reductions in tobacco smoking? Tobacco control. 2006; 15:345-347.

18. Gemignani F, Landi S, Szeszenia-Dabrowska N, Zaridze D, Lissowska J, Rudnai P, Fabianova E, Mates D, Foretova L, Janout V, Bencko V, Gaborieau V, Gioia-Patricola L, et al. 
Development of lung cancer before the age of 50: the role of xenobiotic metabolizing genes. Carcinogenesis. 2007; 28:1287-1293.

19. Landi S, Gemignani F, Canzian F, Gaborieau V, Barale R, Landi D, Szeszenia-Dabrowska N, Zaridze D, Lissowska J, Rudnai P, Fabianova E, Mates D, Foretova L, et al. DNA repair and cell cycle control genes and the risk of youngonset lung cancer. Cancer Res. 2006; 66:11062-11069.

20. Kreuzer M, Pohlabeln H, Ahrens W, Kreienbrock L, BruskeHohlfeld I, Jockel KH, Wichmann HE. Occupational risk factors for lung cancer among young men. Scand J Work Environ Health. 1999; 25:422-429.

21. Inamura K, Takeuchi K, Togashi Y, Hatano S, Ninomiya H, Motoi N, Mun MY, Sakao Y, Okumura S, Nakagawa K, Soda M, Choi YL, Mano H, et al. EML4-ALK lung cancers are characterized by rare other mutations, a TTF-1 cell lineage, an acinar histology, and young onset. Mod Pathol. 2009; 22:508-515.

22. Nagashima O, Ohashi R, Yoshioka Y, Inagaki A, Tajima M, Koinuma Y, Iwakami S, Iwase A, Sasaki S, Tominaga S, Takahashi K. High prevalence of gene abnormalities in young patients with lung cancer. J Thorac Dis. 2013; 5:27-30.
23. VandenBussche CJ, Illei PB, Lin MT, Ettinger DS, Maleki Z. Molecular alterations in non-small cell lung carcinomas of the young. Hum Pathol. 2014; 45:2379-2387.

24. Hsu KH, Ho CC, Hsia TC, Tseng JS, Su KY, Wu MF, Chiu KL, Yang TY, Chen KC, Ooi H, Wu TC, Chen HJ, Chen HY, et al. Identification of five driver gene mutations in patients with treatment-naive lung adenocarcinoma in Taiwan. PLoS One. 2015; 10:e120852.

25. Guo Y, Ma J, Lyu X, Liu H, Wei B, Zhao J, Fu S, Ding L, Zhang J. Non-small cell lung cancer with EML4ALK translocation in Chinese male never-smokers is characterized with early-onset. BMC cancer. 2014; 14:834.

26. Sacher AG, Dahlberg SE, Heng J, Mach S, Janne PA, Oxnard GR. Association Between Younger Age and Targetable Genomic Alterations and Prognosis in NonSmall-Cell Lung Cancer. JAMA oncology. 2016; 2:313-320.

27. Travis W.D. BE, Muller-Hermelink H.K., Harris C.C. World Health Organization Classification of Tumours. Pathology and Genetics of Tumours of the Lung, Pleura, Thymus and Heart. IARC Press: Lyon 2004. 